\title{
Concentração de elementos traços, terras raras e escândio em perfil de intemperismo de rocha metaultramáfica (Bom Jesus da Penha, Minas Gerais)
}

Trace elements, rare earth elements and scandium concentration in a weathering profile of metaultramafic rock (Bom Jesus da Penha, Minas Gerais, Brazil)

\author{
Ilio Rodarte Faria Júnior', George Luiz Luvizotto², Vania Silvia Rosolen² \\ ${ }^{1}$ Programa de Pós-Graduação em Geociências e Meio Ambiente, Instituto de Geociências e Ciências Exatas - IGCE, \\ Universidade Estadual Paulista "Júlio de Mesquita Filho" - UNESP, Rua José Felício Castellano, 2.491, São Miguel, \\ CEP 13506-405, Rio Claro, SP, BR (rdt.ilio@gmail.com) \\ 2Departamento de Petrologia e Metalogenia, Instituto de Geociências e Ciências Exatas - IGCE, Universidade Estadual Paulista \\ "Júlio de Mesquita Filho" - UNESP, Rio Claro, SP, BR (georgell@rc.unesp.br; vrosolen@rc.unesp.br)
}

Recebido em 15 de agosto de 2017; aceito em 10 de abril de 2018

\begin{abstract}
Resumo
O processo de formação dos horizontes lateríticos é responsável pela reorganização química e mineralógica dos litotipos preexistentes. Esse arranjo é controlado pela mineralogia primária da rocha e pelas características de desenvolvimento do processo intempérico. Este artigo apresenta um estudo em um clorita-anfibólio xisto, a partir do qual se desenvolveram dois horizontes de intemperismo. No topo se observou solo caulinítico vermelho argiloso, enquanto abaixo se desenvolve um horizonte saprolítico verde com plintitas de cor ocre, o qual contém montmorillonita neoformada. Os elementos químicos analisados tiveram variações nos teores ao longo desse perfil, sendo que todos os metais tiveram, em determinadas amostras, picos de acúmulos superiores a $100 \%$ em relação à rocha. $\mathrm{Al}_{2} \mathrm{O}_{3}, \mathrm{U}, \mathrm{Th}, \mathrm{Zr}$ e TiO ${ }_{2}$ mostram concentração residual no topo do horizonte de solos, junto a caulinita e óxidos e hidróxidos de ferro; $\mathrm{Fe}_{2} \mathrm{O}_{3}$, $\mathrm{V}$ e Co tiveram maior acúmulo na base do horizonte de solos, próximo à transição para o saprolito; $\mathrm{Mn}, \mathrm{Cr}_{2} \mathrm{O}_{3}, \mathrm{Ni}, \mathrm{Zn}, \mathrm{Cu}$ e elementos terras raras (ETR) apresentaram máximos de enriquecimento no horizonte plintificado, junto a montmorillonita; $\mathrm{CaO}, \mathrm{MgO}$ e $\mathrm{SiO}_{2}$ tiveram redução dos teores ao longo de todo o perfil estudado. Tomando o litotipo metaultramáfico, destacam-se os enriquecimentos dos elementos terras raras e ítrio (ETRY) e escândio (Sc) no perfil de intemperismo, os quais são compatíveis com modelos de mineralização laterítica.
\end{abstract}

Palavras-chave: Enriquecimento laterítico; Greenstone Belt Morro do Ferro; Clorita-anfibólio xisto; Argilominerais neoformados; Escândio.

\begin{abstract}
The development of lateritic horizons is responsible for chemical and mineralogical reorganization in the parent rock. The final arrangement is controlled by the primary composition of the parent material, climate conditions, the presence of living organisms, topography, and time. This work presents chemical data on two weathering horizons developed from chlorite-amphibole schist. The upper horizon is composed of a red clayey kaolinitic soil. A green saprolitic horizon with ocher plinthite and neoformed montmorillonite occurs below it. Concentrations of analyzed elements vary along the soil profile and all of the metals have peak concentrations that are $100 \%$ higher than the parent rock. The upper part of the soil profile is enriched with $\mathrm{Al}_{2} \mathrm{O}_{3}, \mathrm{U}, \mathrm{Th}, \mathrm{Zr}$ and $\mathrm{TiO}_{2}$ as well as with kaolinite and iron oxide-hydroxides. The highest concentrations of $\mathrm{Fe}_{2} \mathrm{O}_{3}, \mathrm{~V}$ and $\mathrm{Co}$ occur in the transition zone between the soil and saprolite horizons. On the other hand, the highest values of $\mathrm{Mn}, \mathrm{Cr}_{2} \mathrm{O}_{3}, \mathrm{Ni}, \mathrm{Zn}, \mathrm{Cu}$ and Rare Earth Elements occur in the montmorillonite-bearing saprolite horizon. $\mathrm{CaO}, \mathrm{MgO}$ and $\mathrm{SiO}_{2}$ are depleted along the profile. Considering the metaultramafic composition of the parent rock, we highlight the notable enrichment of rare earth elements, yttrium and scandium in the weathering profile, which can be compared to the lateritic mineralization models of these elements.
\end{abstract}

Keywords: Lateritic enrichment; Morro do Ferro Greenstone Belt; Chlorite-amphibole schists; Neoformed clay minerals; Scandium. 


\section{INTRODUÇÃO}

Os perfis lateríticos são o resultado de intenso intemperismo químico nas rochas sob clima tropical e subtropical. São comuns na paisagem brasileira, podendo haver, em um mesmo perfil, características que apontam para a sobreposição de mais de um período de lateritização (Trescases e Oliveira, 1978; Melfi et al., 1980; Dardenne e Schobenhaus, 2001).

O estudo sobre os perfis de intemperismo é importante devido a seus aspectos econômicos, podendo compor concentrações metálicas residuais, de minerais resistatos ou de mineralogias neoformadas (Butt, 1975; Smirnov, 1982). Também são alvo de interesse de outras áreas do conhecimento por serem parte da interação do homem com o meio geológico, a exemplo da geotecnia, engenharia civil, geologia ambiental, agronomia e saúde (Retallack, 2010).

O processo laterítico é responsável pelo rearranjo físico, químico e mineralógico do substrato geológico e ocorre em condições climáticas e tectônicas específicas. Os perfis lateríticos possuem associações químicas e mineralógicas resultantes da transformação dos silicatos por reação de hidrólise em ambiente quente e úmido, e frequentemente se associam a formas de relevo tabulares com relativa estabilidade tectônica (Melfi et al., 1980; Golightly, 1981; Thorne, 2011; Marsh et al., 2013).

Os metais e os elementos terras raras (ETR) apresentam comportamento geoquímico que permite suas concentrações em perfis lateríticos. Nessas condições, as concentrações podem se dar de forma residual, em minerais resistentes ao intemperismo, ou devido à mobilidade vertical e/ou lateral dos elementos, seguida de incorporação na estrutura de minerais neoformados ou adsorvidos em suas superfícies (Nesbitt, 1979; Golightly, 1981; Bao e Zhao, 2008; Marsh et al., 2013). Por fim, a concentração de determinados metais é complementada pela lixiviação de elementos móveis nessas condições (Nesbitt, 1979).

O objetivo deste artigo foi apresentar os produtos do intemperismo de uma rocha metaultramáfica na região de Bom Jesus da Penha (MG), focando no comportamento e na concentração dos elementos químicos ao longo do perfil de intemperismo do clorita-anfibólio xisto. O domínio geológico-geomorfológico no qual os perfis estão inseridos caracteriza uma ampla área da porção sul-sudoeste de Minas Gerais, onde as rochas do Greenstone Belt Morro do Ferro (GBMF) apresentam expressiva distribuição (Teixeira, 1978; Zanardo, 2003). Do ponto de vista da geologia econômica, esse fato é de grande importância devido à vocação desses litotipos para gênese, entre outras, de concentrações metálicas lateríticas (Dardenne e Schobenhaus, 2001; Marsh e Anderson, 2011; Marsh et al., 2013).

\section{MATERIAIS E MÉTODOS}

\section{Área de estudo e caracterização geológica/geomorfológica regional}

A área de estudo localiza-se no sudoeste de Minas Gerais (Figura 1), na Rodovia BR-265, aproximadamente 6 $\mathrm{km}$ a nordeste de Bom Jesus da Penha (coordenadas $20^{\circ} 59^{\prime} 6.03$ 'S, $46^{\circ} 29^{\prime} 34.78^{\prime}$ 'O). Está situada na porção limítrofe dos litotipos aflorantes do Cráton do São Francisco e da Província Estrutural Tocantins (Almeida, 1981), com unidades geológicas de evoluções tectono-metamórficas, idades e gêneses distintas (Almeida, 1981; Zanardo, 1992; Brito Neves et al., 1999; Valeriano et al., 2004; entre outros).

Na região aflora terreno tipo granito-greenstone, pertencente ao Cráton São Francisco (Almeida, 1981). O Complexo Barbacena, domínio arqueano/paleoproterozoico, é composto de granitoides e biotita e/ou anfibólio gnaisses bandados (Hasui et al., 1988; Zanardo, 1992). O GBMF (Teixeira, 1978) é composto de sequências metavulcanossedimentares na forma de faixas alongadas segundo a direção $\mathrm{WNW}$, com ramificação para $\mathrm{E}-\mathrm{W}$ na região de Jacuí, que se colocam embutidas por contatos tectônicos no Complexo Barbacena e no Grupo Araxá (Feola, 2004). Nessa unidade predominam rochas ultramáficas de composição komatiítica, rochas metabásicas de composição komatíítica, toleítica e, em menor escala, cálcio-alcalina (Teixeira e Danni, 1979; Zanardo, 1992, 2003; Carvalho et al., 1992).

O Grupo Araxá, domínio Neoproterozoico, é representado por sequência metassedimentar com contribuição de rochas vulcânicas e vulcanoclásticas (p. ex. Barbosa et al., 1970; Zanardo et al., 1990; Simões, 1995). Essa unidade se instala na forma de cavalgamento de baixo ângulo (Simões, 1995). No fim do evento Brasiliano todas essas unidades foram afetadas, em diferentes graus, por sistemas de cisalhamento direcionais (Morales, 1993).

As características estruturais são fundamentais na compartimentação geomorfológica, uma vez que as unidades de relevo com perfis lateríticos são fortemente influenciadas pelo arranjo e pela distribuição dos litotipos. A área de estudo se insere na unidade geomorfológica Planalto Poços de Caldas-Varginha (Figura 1), composta de colinas e morros, por vezes alongados, com vertentes convexo-côncavas e topos convexos a aplainados. Predominam os Latossolos Vermelho-Amarelo e Vermelho-Escuro, podendo ocorrer Argissolos e Cambissolos (RADAMBRASIL, 1983). Essa região apresenta clima tropical de altitude, com duas estações bem definidas, temperatura média anual de 18 a $20^{\circ} \mathrm{C}$ e pluviosidade de 1.500 a $1.700 \mathrm{~mm}$ anuais (RADAMBRASIL, 1983). 


\section{Descrição de afloramentos e coleta de amostras}

Foi descrito o perfil de intemperismo típico desenvolvido a partir de clorita-anfibólio xisto aflorante na região, acompanhado de registro por fotos. Para caracterização química e mineralógica, foram coletadas seis amostras no domínio de ocorrência de rocha metaultramáfica, cujas profundidades podem ser observadas na Figura 2.

A espessura máxima do horizonte plintificado foi estipulada tomando sua cota superior como equivalente ao afloramento descrito no topo do platô e sua cota mínima possível foi inferida com base no afloramento de rocha não intemperizada de maior elevação identificado em campo. Apesar disso, a sobreposição de intemperismo mais jovem que o perfil, as condições geomorfológicas e a ausência de inserção erosiva localizada, como ravinas, impossibilitam observar a totalidade de sua extensão vertical (Faria Júnior, 2015). Nesse local, o topo desse horizonte somente foi identificado em exposição de corte de estrada, onde exibiu espessura aflorante da ordem de $5 \mathrm{~m}$.

\section{Caracterização mineralógica e química}

As amostras coletadas foram quarteadas, secadas, moídas em cadinho de porcelana e peneiradas. Na sequência, a

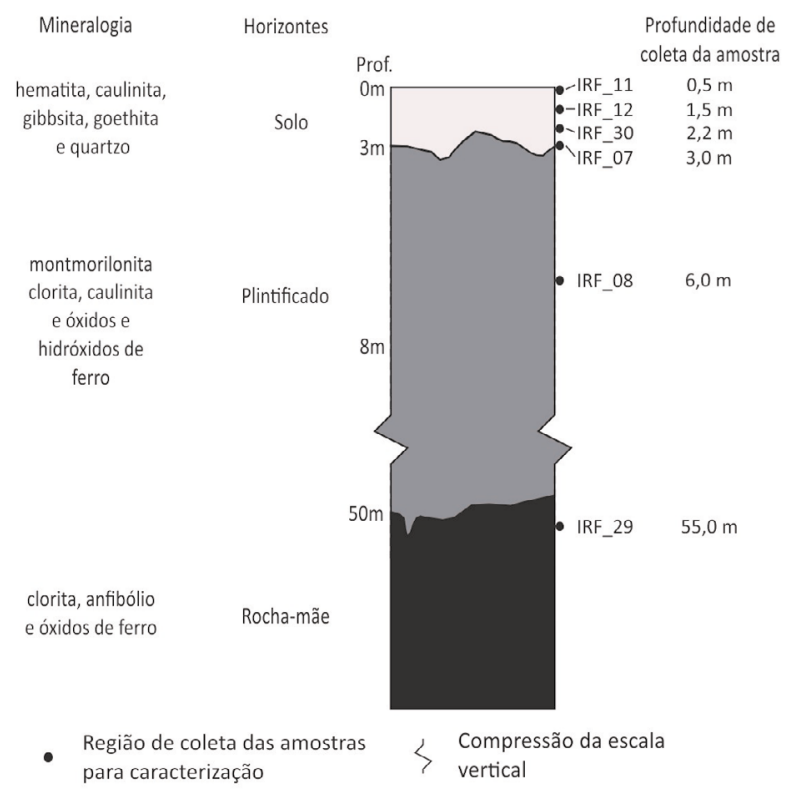

Figura 2. Perfil de intemperismo esquemático, profundidade de coleta de amostras e resultados da caracterização mineralógica do clorita-anfibólio xisto e respectivos horizontes de intemperismo. A profundidade de coleta das amostras se dá em relação ao ápice topográfico do platô no domínio da rocha metaultramáfica (cota de $1.150 \mathrm{~m}$ ).
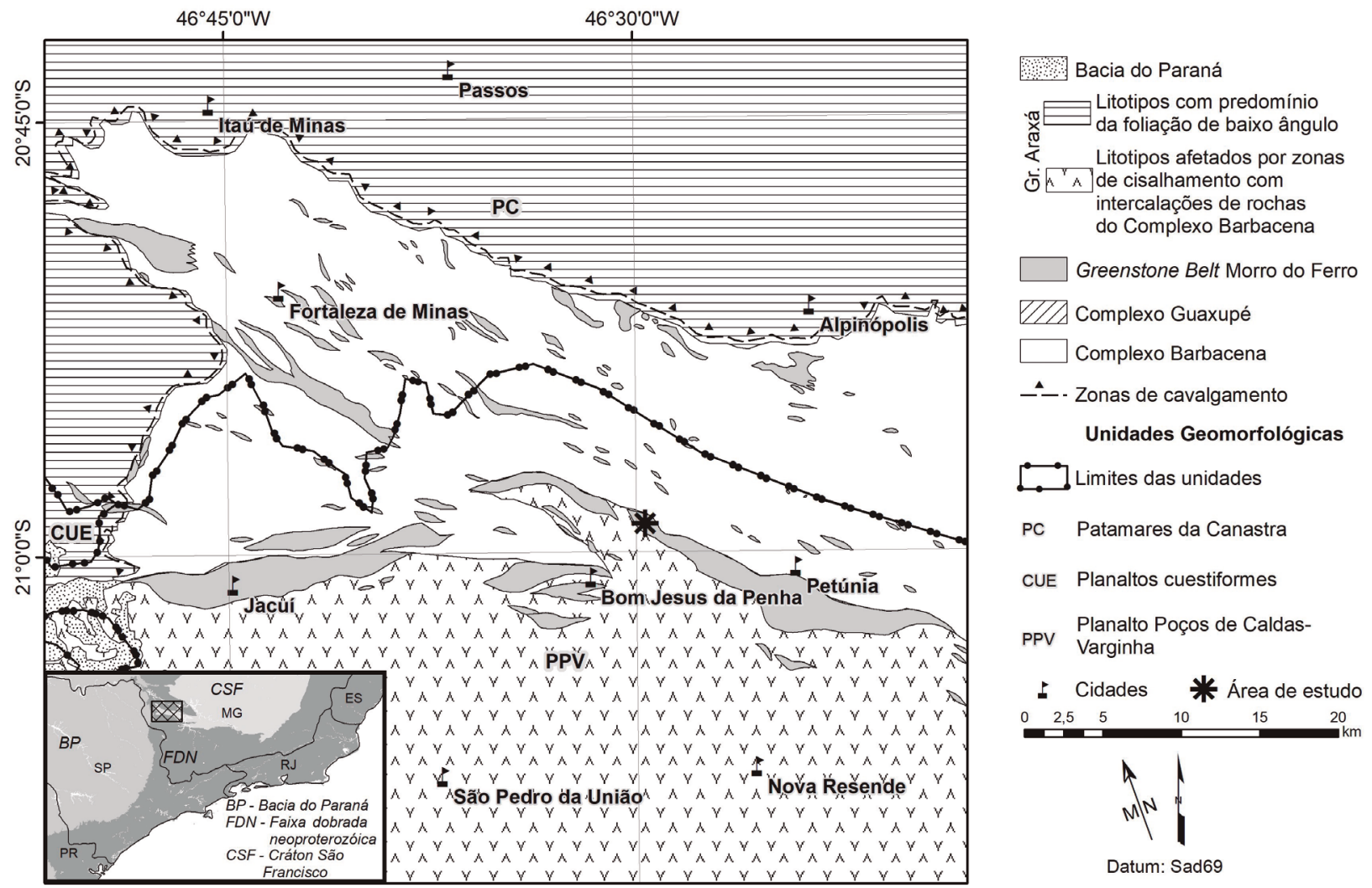

Figura 1. Mapa geológico regional (adaptada de Zanardo, 2003), unidades geomorfológicas (modificado de RADAMBRASIL, 1983) e localização da área de estudo. 
caracterização mineralógica de amostra total foi feita por difratometria de raios $\mathrm{X}$, em equipamento PANalytical EMPYREAN (Departamento de Petrologia e Metalogenia da Universidade Estadual Paulista "Júlio de Mesquita Filho" - UNESP - Rio Claro), realizada com radiação de cobre (WL=1,54056 $\AA$ ) e filtro de níquel, enquanto medidas foram feitas ao passo de $3,8^{\circ}$ " e tamanho do passo de $0,008^{\circ}$ (velocidade de scan de $0,27^{\circ} / \mathrm{s}$ ), no intervalo de $3^{\circ}<2 \theta<65^{\circ}$, cujo tempo total de análise foi de 3'52" (tempo reduzido em $40 \%$ pelo X'Celerator), com corrente de $30 \mathrm{~mA}$ e voltagem de $40 \mathrm{kV}$. A descrição petrográfica das seções delgadas da rocha por luz transmitida foi feita em microscópio óptico convencional, Zeiss Axioskop A1.

A preparação das amostras e a análise química da rocha e do material intemperizado foram feitas pelo Laboratório Acme (Analytical Laboratories LTD, Vancouver, Canadá). Foram determinados os teores de $\mathrm{SiO}_{2}, \mathrm{TiO}_{2}, \mathrm{Al}_{2} \mathrm{O}_{3}, \mathrm{Fe}_{2} \mathrm{O}_{3}$, $\mathrm{MnO}, \mathrm{MgO}, \mathrm{CaO}, \mathrm{Na}_{2} \mathrm{O}$ e $\mathrm{K}_{2} \mathrm{O}$ por ICP-OES (Espectrometria de Emissão Óptica com Plasma Indutivamente Acoplado), após fusão utilizando metaborato/tetraborado de lítio. Os elementos Th, $\mathrm{Pb}, \mathrm{Zn}, \mathrm{Cu}, \mathrm{Ni}, \mathrm{V}, \mathrm{Cr}_{2} \mathrm{O}_{3}, \mathrm{Co}, \mathrm{U}, \mathrm{Zr}$, ETR (La, $\mathrm{Ce}, \mathrm{Pr}, \mathrm{Nd}, \mathrm{Sm}, \mathrm{Eu}, \mathrm{Gd}, \mathrm{Tb}, \mathrm{Dy}, \mathrm{Ho}, \mathrm{Er}, \mathrm{Tm}, \mathrm{Yb}$ e Lu), Y e Sc foram analisados por Espectrômetro de Massa com Plasma Acoplado Indutivamente (ICP-MS), após digestão de amostras sólidas em água régia. A perda ao fogo (LOI) foi determinada, antes da fusão da amostra, pela diferença de peso dos exemplares antes e depois do aquecimento a $1.000^{\circ} \mathrm{C}$ por 4 horas.

\section{Determinação do índice de intemperismo e de enriquecimento geoquímico}

Para determinar a variação do grau de intemperismo, efetuou-se o cálculo do chemical index of alteration (CIA) seguindo a fórmula proposta por Nesbitt e Young (1982) com base nos pesos molares (Equação 1):

$\mathrm{CIA}=\left[\left(\mathrm{Al}_{2} \mathrm{O}_{3}\right) /\left(\mathrm{Al}_{2} \mathrm{O}_{3}+\mathrm{CaO}+\mathrm{K}_{2} \mathrm{O}+\mathrm{Na}_{2} \mathrm{O}\right)\right] \times 100$

Quanto mais próximo a 100 for o resultado, maior o grau de intemperismo químico, já que este é responsável pela lixiviação do cálcio, potássio e do sódio.

O cálculo do fator de enriquecimento relativo dos elementos ao longo do perfil de intemperismo foi feito utilizando-se o elemento vanádio $(\mathrm{V})$ como invariante no processo de intemperismo químico para normalização do conteúdo dos demais elementos (Thorne, 2011). Aplicou-se aqui o V por se tratar do elemento químico com menor variação ao longo do perfil. Uma simplificação do cálculo de Nesbitt (1979) apresentado em Thorne (2011), o qual contribui para a visualização gráfica, obedece à Equação 2:

Fator de enriquecimento $=(\mathrm{Ce}, \mathrm{hz} / \mathrm{Ci}, \mathrm{hz}) /(\mathrm{Ce}, \mathrm{rm} / \mathrm{Ci}, \mathrm{rm})$
Em que:

Ce,hz: teor de determinado elemento no horizonte de intemperismo;

Ci,hz: teor do elemento imóvel no horizonte de intemperismo; $\mathrm{Ce}, \mathrm{rm}$ : teor de determinado elemento na rocha;

$\mathrm{Ci}, \mathrm{rm}$ : teor do elemento imóvel na rocha.

Como resultado, relações inferiores a 1 (número adimensional) descrevem perda relativa do elemento e superiores a 1 mostram enriquecimento relativo. Valores iguais a 1 evidenciam estabilidade relativa na amostra.

$\mathrm{O}$ cério anômalo $(\mathrm{Ce} / \mathrm{Ce} *)$, utilizado como indicativo da oxidação desse elemento e de sua mobilidade diferencial diante dos demais ETR (Prudêncio et al., 1995; Lawrence et al., 2006), foi calculado pela equação de Lawrence et al. (2006) (Equação 3):

$\mathrm{Ce} / \mathrm{Ce}^{*}=\mathrm{Ce}_{\mathrm{N}} /\left(\operatorname{Pr}_{\mathrm{N}}{ }^{2} / \mathrm{Nd}_{\mathrm{N}}\right)$

\section{RESULTADOS E DISCUSSÃO}

\section{Perfil de intemperismo}

Foi identificada nessa região a presença de biotita gnaisses, clorita-anfibólio xisto e quartzitos. Esses litotipos se organizam por meio de contatos tectônicos de alto ângulo, segundo a direção NW-SE, orientação idem àquela da foliação impressa nessas rochas.

Associados ao clorita-anfibólio xisto foram observados dois distintos horizontes de intemperismo (Figura 2). O perfil encontra-se em um platô, com cota máxima em $1.150 \mathrm{~m}$, topo de baixa declividade e maior extensão segundo a direção NW-SE, sendo que a base do perfil foi identificada na cota de $950 \mathrm{~m}$ de altitude.

O horizonte de solo, que ocupa a região topograficamente mais alta e de menor declividade do relevo, apresentou espessura da ordem de $3 \mathrm{~m}$. Esse solo tem cor predominantemente vermelha (Figura 3), é argiloso, com baixa contribuição de quartzo visível (inferior a 10\%) e presença de nódulos ferruginosos (petroplintitas), os quais tendem a ser esféricos, de tamanho inferior a $1 \mathrm{~cm}$.

A transição do solo para o saprolito é gradativa, devido à variação da inserção dos processos pedogenéticos. É marcada por mudança na cor, de vermelho intenso (topo dos solos) para ocre (base dos solos); posteriormente, no saprolito a cor verde se sobrepõe ao tom ocre da base dos solos. Essa passagem é marcada, então, pela substituição de argilas de cor vermelha por aquelas de cor verde. Ao se adentrar o horizonte saprolítico, de coloração esverdeada, nota-se, ainda, influência de cor ocre, a qual diminui em direção à sua base. Junto a isso, nota-se, no saprolito, a preservação da fábrica original da rocha. Exemplo da região de transição, a 
amostra IRF-07 se encontra na base do horizonte de solos, próximo à transição para o horizonte plintificado, em que a cor é ocre e não são observadas estruturas que remetam à rocha-mãe.

O horizonte saprolítico é plintificado, onde predomina a cor verde com dispersas plintitas de cor ocre. Coloca-se abaixo do horizonte de solos, com espessura aflorante de $5 \mathrm{~m}$. As plintitas possuem formato esférico e diâmetro subcentimétrico. Também podem compor faixas de cor ocre, obedecendo a planos preexistentes (Figura 4), com continuidade variada e espessura geralmente inferior a $5 \mathrm{~cm}$.

O saprolito é relativamente homogêneo, sem expressivas mudanças visíveis nesse afloramento. É friável, com a fábrica original da rocha facilmente identificável. A mineralogia primária foi substituída, quase totalmente, por argilominerais, restando esparsos anfibólios com hábito ripiforme, que se dispõem paralelos à direção da foliação. Identificam-se, como minerais neoformados, argilas de cor verde e óxidos e hidróxidos de ferro, com cor ocre ou ocre-avermelhado. Os óxidos e hidróxidos de ferro podem formar localizadas concreções, as quais são subcentimétricas e se localizam em planos de junta preexistentes.

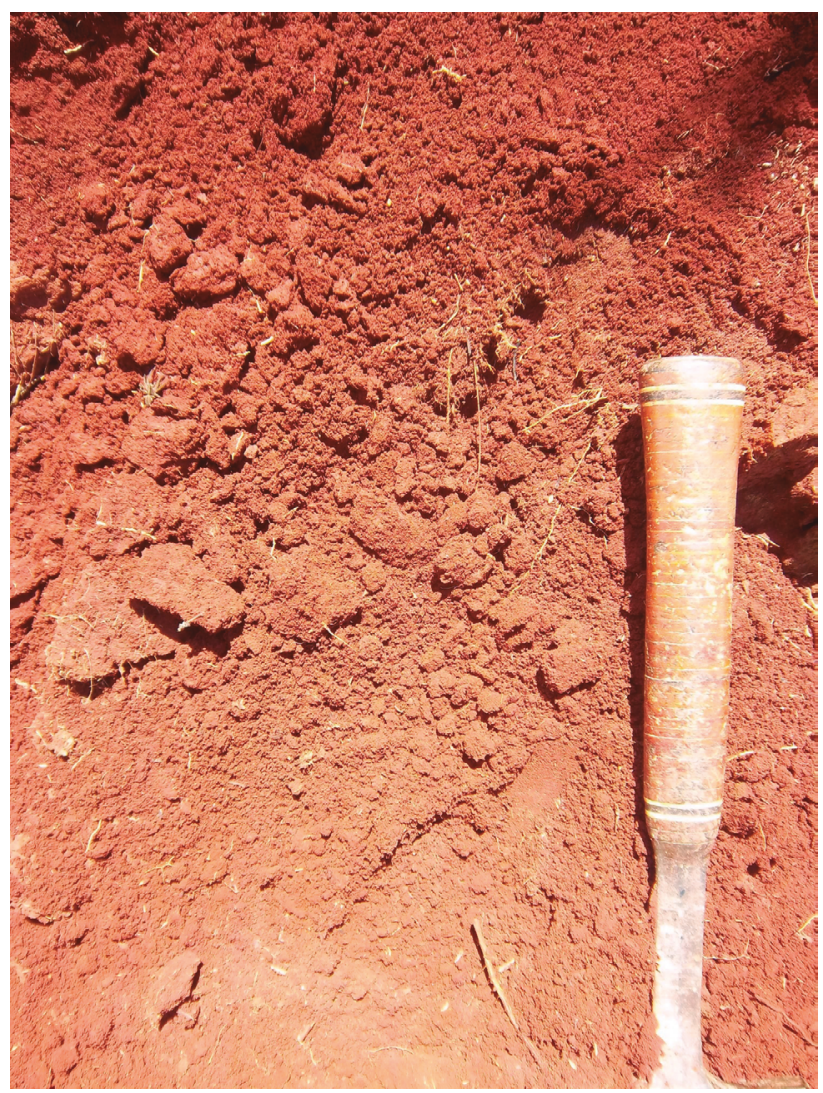

Figura 3. Solo vermelho argiloso desenvolvido a partir de clorita-anfibólio xisto.
Não é possível identificar o perfil de intemperismo completo em um mesmo afloramento. Com isso, a rocha foi descrita a sudeste (aproximadamente 2,2 km) de onde se encontrou os dois horizontes superiores, em drenagem, $50 \mathrm{~m}$ abaixo do ápice do platô local, e situada na extensão desse mesmo corpo (Feola, 2004).

O clorita-anfibólio xisto tem cor verde-escuro, com foliação marcada por cristais de clorita, com hábito planar e tamanho inferior a $0,5 \mathrm{~cm}$, que se orientam de forma subvertical na direção NW-SE. Os cristais de anfibólio se colocam como ripas menores que $0,5 \mathrm{~cm}$, paralelas à direção da foliação. Em análise de campo não foram identificados nesse afloramento minerais neoformados pelo processo intempérico.

\section{Caracterização mineralógica, química e petrográfica do perfil de intemperismo}

As amostras do horizonte de solo, no domínio da rocha metaultramáfica, apresentam, como mineralogia principal, caulinita, hematita, goethita, gibbsita e quartzo (Figura 5).

Já o saprolito desse xisto mostrou a presença de clinocloro (variedade de clorita), montmorillonita (argila do grupo das esmectitas) e caulinita (Figura 5).

A caracterização petrográfica da rocha mostrou a presença de cristais de tremolita/actinolita $(70 \%)$, clorita (26\%), hidróxido de ferro $(3 \%)$ e opacos $(<1 \%)$, compondo um clorita-anfibólio xisto.

A composição mineralógica do litotipo é condizente com descrições apresentadas para o GBMF nessa região (Zanardo, 2003; Feola, 2004). O perfil de intemperismo é formado por argilas 1:1 (caulinitas), acompanhadas de óxidos e hidróxidos de ferro, nos solos e por argilas 2:1 (esmectitas) no horizonte saprolítico. Essa distribuição mineralógica ao

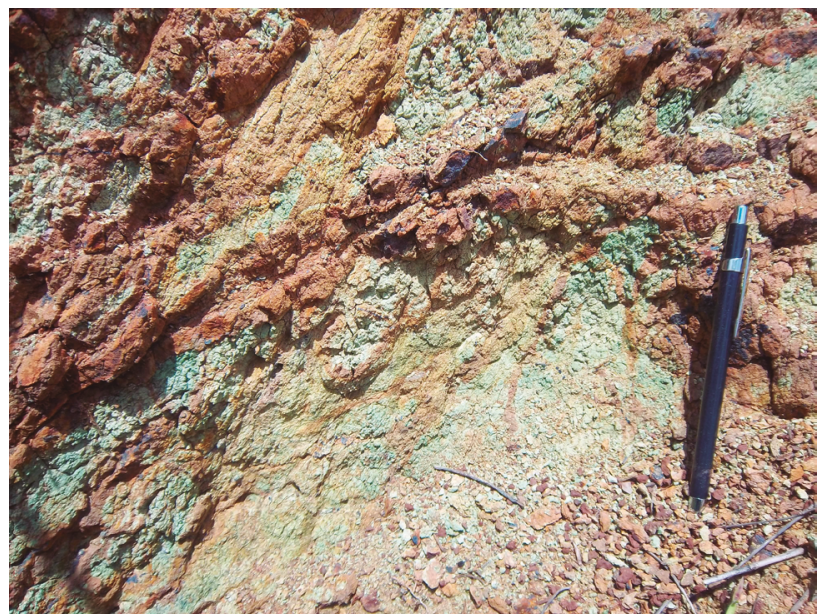

Figura 4. Horizonte plintificado, desenvolvido a partir de clorita-anfibólio xisto, mostra cor verde com plintitas e faixas de cor ocre, além de nódulos de óxido de ferro em planos de junta. 
longo do perfil de intemperismo remete à arquitetura típica de perfis lateríticos desenvolvidos em rochas (meta)máficas/ (meta)ultramáficas (Marsh et al., 2013). Dessa forma, acompanhando as mudanças mineralógicas, também se observa a variação dos elementos químicos ao longo dos horizontes intempéricos desenvolvidos a partir da rocha metaultramáfica (Tabelas 1 e 2).

O CIA mostra (Tabela 1) valores reduzindo do topo para a base do perfil laterítico. Com isso, exibe maior grau de intemperismo no horizonte de solos quando comparado ao saprolito. Esses resultados são condizentes com as mineralogias identificadas por intermédio da caracterização dos horizontes de solo e saprolítico. O grau de intemperismo mostra maior intensidade na região de monossialitização, resultando em argilominerais do tipo 1:1, seguido de redução de seu nível no horizonte de argilas bissialíticas (2:1).

Os elementos maiores e menores apresentam variação em seu conteúdo de acordo com o grau de intemperismo (Figura 6). A rocha apresenta teores totais de $\mathrm{Na}_{2} \mathrm{O}$ e $\mathrm{K}_{2} \mathrm{O}$ inexpressivos $(0,11$ e $0,02 \%$, respectivamente). Os conteúdos de $\mathrm{MgO}$ e $\mathrm{CaO}$ mostram, nos horizontes de intemperismo, valores significativamente inferiores à rocha, indicando lixiviação desses álcalis com o aumento do CIA (Tardy e Nahon, 1985). $\mathrm{SiO}_{2}$ tem seus menores valores no

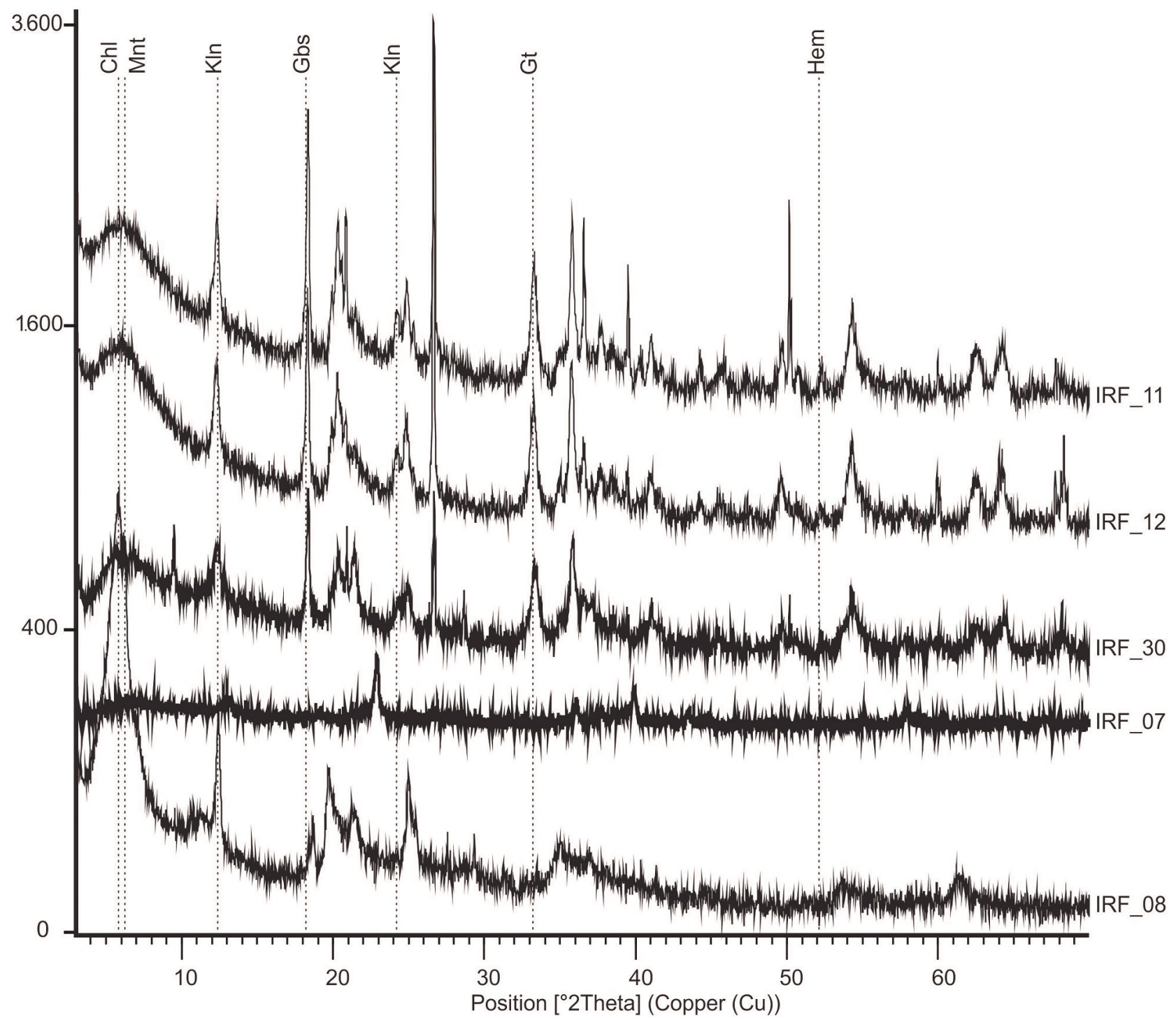

Chl: clorita; Mnt: montmorillonita; KIn: caulinita; Gbs: gibbsita; Gt: goethita; Hem: hematita.

Figura 5. Difratograma de raios $X$ de amostras do perfil de intemperismo. $O$ empilhamento dos difratogramas reflete a distribuição em profundidade das amostras coletadas. As Amostras IRF-11, 12, 30 e 07 referem-se aos solos vermelhos, enquanto IRF-08 refere-se ao horizonte plintificado. 
horizonte de solos, nos quais prevalecem argilominerais do tipo 1:1, com diminuto conteúdo na base desse horizonte. Já no horizonte saprolítico, em que predominam argilas do tipo 2:1, esse conteúdo é superior aos solos, porém inferior à rocha, mostrando, mesmo no saprolito, a lixiviação desse elemento. Na rocha não intemperizada seu teor é condizente com litotipos ultrabásicos. $\mathrm{Fe}_{2} \mathrm{O}_{3}$ e $\mathrm{Al}_{2} \mathrm{O}_{3}$, como esperado, apresentam maiores conteúdos no horizonte de solos, nos quais são descritos oxi-hidróxidos desses elementos.

Os teores de V são relativamente constantes ao longo do perfil, com leve aumento na base do horizonte de solos (IRF-07), o qual pode se associar ao pico de teor de $\mathrm{Fe}_{2} \mathrm{O}_{3}$, dada a coprecipitação desse elemento junto aos óxidos de ferro (Wright e Belitz, 2010), ou ter incremento associado a minerais resistatos (Hill et al., 2000). Já os teores de U, $\mathrm{Th}, \mathrm{Zr}$ e $\mathrm{TiO}_{2}$ mostram incremento em direção ao topo do perfil, acompanhando o grau de intemperismo.

$\mathrm{Co}, \mathrm{Mn}$ e $\mathrm{Cr}_{2} \mathrm{O}_{3}$ apresentam aumento contínuo de seus teores em direção à base do perfil, seguindo a redução do CIA. Os valores analisados nos horizontes intemperizados são superiores àqueles dos respectivos elementos na rocha. Co atinge o ápice de valor na base dos solos (IRF-07) devido à afinidade desse elemento com oxi-hidróxidos de Fe (Marsh et al., 2013). Já $\mathrm{Mn} \mathrm{e} \mathrm{Cr}_{2} \mathrm{O}_{3}$ mostram altos conteúdos na base dos solos e no horizonte saprolítico, podendo indicar fixação como fase óxido desses elementos (Oze, 2003).

$\mathrm{Ni}, \mathrm{Zn}$ e $\mathrm{Cu}$ mostram leve, porém gradual, incremento nos teores do topo até a base do horizonte de solos. Contudo, nesse horizonte, é comum a presença de valores inferiores à rocha. Já ao atingir o horizonte plintificado esses metais mostram abrupto aumento de seus conteúdos absolutos. Nesse local, junto a montmorillonitas, argilominerais do tipo 2:1, os teores superam o conteúdo da rocha. Ni e Zn podem ser incorporados à estrutura dos argilominerais do tipo 2:1 (Trescases, 1975; Reimann e Caritat, 1998; Marsh et al., 2013), enquanto $\mathrm{Cu}$ comumente se associa à goethita no horizonte plintificado (Reimann e Caritat, 1998).

O conjunto de elementos apresenta, assim, redistribuição de seus teores compatível com a ação do processo laterítico (Nesbitt, 1979; Golightly, 1981; Smirnov, 1982; Tardy e Nahon, 1985; Marsh et al., 2013). Na Tabela 3 são apresentados os picos de concentrações dos principais metais e os respectivos graus de intemperismo do perfil; nessa representação nota-se que os elementos químicos mostram grupos

Tabela 1. Composição geoquímica dos elementos químicos maiores e menores da rocha metaultramáfica e de seus horizontes de intemperismo.

\begin{tabular}{|c|c|c|c|c|c|c|c|c|}
\hline \multirow{3}{*}{ Analito } & \multirow{3}{*}{ Unidade } & \multirow{3}{*}{$\begin{array}{l}\text { Limite de } \\
\text { detecção }\end{array}$} & \multicolumn{6}{|c|}{ Amostra } \\
\hline & & & \multicolumn{4}{|c|}{ Solos } & \multirow{2}{*}{$\begin{array}{c}\text { Hz. Plintificado } \\
\text { IRF-08 }\end{array}$} & \multirow{2}{*}{$\begin{array}{c}\text { Rocha-mãe } \\
\text { IRF-29 }\end{array}$} \\
\hline & & & IRF-11 & IRF-12 & IRF-30 & IRF-07 & & \\
\hline $\mathrm{SiO}_{2}$ & $\%$ & 0,010 & 31,020 & 32,210 & 23,830 & 19,900 & 36,820 & 44,120 \\
\hline $\mathrm{TiO}_{2}$ & $\%$ & 0,010 & 2,020 & 1,850 & 1,720 & 1,850 & 1,050 & 0,240 \\
\hline $\mathrm{Al}_{2} \mathrm{O}_{3}$ & $\%$ & 0,010 & 31,090 & 27,980 & 24,560 & 20,130 & 12,660 & 9,860 \\
\hline $\mathrm{Fe}_{2} \mathrm{O}_{3}$ & $\%$ & 0,040 & 18,440 & 20,150 & 29,630 & 40,260 & 23,900 & 10,880 \\
\hline $\mathrm{MnO}$ & $\%$ & 0,010 & 0,050 & 0,060 & 0,140 & 0,200 & 0,220 & 0,160 \\
\hline $\mathrm{MgO}$ & $\%$ & 0,010 & 0,030 & 0,210 & 1,500 & 0,040 & 2,710 & 21,490 \\
\hline $\mathrm{CaO}$ & $\%$ & 0,010 & 0,010 & 0,030 & 0,030 & 0,020 & 0,340 & 5,920 \\
\hline $\mathrm{Na}_{2} \mathrm{O}$ & $\%$ & 0,010 & $<0,010$ & $<0,010$ & $<0,010$ & $<0,010$ & 0,010 & 0,110 \\
\hline $\mathrm{K}_{2} \mathrm{O}$ & $\%$ & 0,010 & 0,030 & 0,040 & 0,020 & $<0,010$ & 0,050 & 0,020 \\
\hline $\mathrm{Cr}_{2} \mathrm{O}_{3}$ & $\%$ & 0,002 & 0,176 & 0,241 & 0,815 & 1,088 & 1,145 & 0,346 \\
\hline Th & ppm & 0,010 & 11,900 & 9,800 & 4,700 & 0,800 & 0,900 & $<0,200$ \\
\hline $\mathrm{Pb}$ & ppm & 0,100 & 10,500 & 11,700 & 14,300 & 1 & 9,400 & 0,900 \\
\hline $\mathrm{Zn}$ & ppm & 1,000 & 12 & 76,000 & 41,000 & 109 & 939 & 15 \\
\hline $\mathrm{Cu}$ & ppm & 0,100 & 20,400 & 86,800 & 66,200 & 324,200 & $1.035,100$ & 20,600 \\
\hline $\mathrm{Ni}$ & ppm & 20,000 & 113 & 379 & 804 & 1.246 & 4.204 & 1.198 \\
\hline V & ppm & 8,000 & 277 & 244 & 438 & 512 & 222 & 167 \\
\hline $\mathrm{Zr}$ & ppm & 0,100 & 402 & 322,500 & 180,400 & 113,300 & 86,300 & 12,400 \\
\hline$U$ & ppm & 0,100 & 2,400 & 2 & 1,200 & 0,300 & 0,300 & $<0,100$ \\
\hline Co & ppm & 0,200 & 9,400 & 16,200 & 95,400 & 204,900 & 172,400 & 85,200 \\
\hline Soma & $\%$ & & 99,830 & 99,820 & 99,820 & 99,730 & 99,300 & 99,910 \\
\hline LOI & $\%$ & & 16,900 & 16,900 & 17,300 & 16 & 19,800 & 6,600 \\
\hline \multicolumn{2}{|c|}{$\begin{array}{l}\text { CIA (Nesbitt e } \\
\text { Young, 1982) }\end{array}$} & & 99,800 & 99,600 & 99,600 & 99,700 & 94,800 & 47,300 \\
\hline
\end{tabular}


com comportamentos geoquímicos similares, o que os leva a apresentar picos de teores associados às fases mineralógicas residuais ou neoformadas no perfil de intemperismo.

Os álcalis $\mathrm{CaO}$ e $\mathrm{MgO}$, devido à lixiviação, mostram forte empobrecimento (Figura 7) ao longo dos horizontes de intemperismo, em especial naquele de solos. No saprolito, em que argilas do tipo 2:1 apresentam $\mathrm{MgO}$ em sua estrutura e também ocorrem resquícios de minerais preservados, o empobrecimento desse elemento é o menor no perfil laterítico. O comportamento estável de $\mathrm{K}_{2} \mathrm{O}$ reflete $\mathrm{o}$ baixo conteúdo total desse elemento.

Durante a normalização parte dos elementos apresenta efeito gráfico de redução na amostra IRF-07. Nesse caso, a situação pode ser explicada pela variação do teor do elemento normalizador (V), que atinge seu maior valor nessa amostra.

$\mathrm{Al}_{2} \mathrm{O}_{3}$ e $\mathrm{Fe}_{2} \mathrm{O}_{3}$ mostram estabilidade ao longo do perfil, com leve enriquecimento do primeiro apenas no topo dos solos, enquanto o segundo mostra enriquecimento no horizonte plintificado. Os resultados apontam a preservação desses elementos diante do processo intempérico, com baixa mobilidade vertical. Assim, as variações dos teores absolutos desses elementos se originam da oscilação dos conteúdos dos demais elementos ao longo dos horizontes.

$\mathrm{SiO}_{2}$ apresenta constante empobrecimento nos horizontes de intemperismo. Novamente, essa distribuição é coerente com a composição mineralógica do perfil, já que nos solos predominam argilominerais do tipo 1:1 (monossialíticas), enquanto no saprolito esses são do tipo 2:1 (bissialíticas). Comparativamente, o segundo argilomineral apresenta maior conteúdo de $\mathrm{SiO}_{2}$ do que o primeiro (Pearson, 1978).

Os metais comportam-se de três formas distintas no perfil de intemperismo, o que reflete a variação do CIA. A distinção desses comportamentos de enriquecimento corrobora o comportamento descrito na Tabela 2.

Tabela 2. Composição geoquímica dos elementos terras raras, ítrio e escândio na rocha metaultramáfica e de seus horizontes de intemperismo.

\begin{tabular}{|c|c|c|c|c|c|c|c|c|c|}
\hline & \multirow{3}{*}{ Analito } & \multirow{3}{*}{ Unidade } & \multirow{3}{*}{$\begin{array}{l}\text { Limite de } \\
\text { detecção }\end{array}$} & \multicolumn{6}{|c|}{ Amostra } \\
\hline & & & & \multicolumn{4}{|c|}{ Solos } & \multirow{2}{*}{$\begin{array}{c}\text { Hz. Plintificado } \\
\text { IRF-08 }\end{array}$} & \multirow{2}{*}{$\begin{array}{c}\text { Rocha-mãe } \\
\text { IRF-29 }\end{array}$} \\
\hline & & & & IRF-11 & IRF-12 & IRF-30 & IRF-07 & & \\
\hline \multirow{5}{*}{ 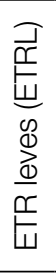 } & $\mathrm{La}$ & ppm & 0,100 & 5,200 & 32,600 & 5 & 8,200 & 425,400 & 1,900 \\
\hline & $\mathrm{Ce}$ & ppm & 0,100 & 14,300 & 15,000 & 30,800 & 17,700 & 38,600 & 1,900 \\
\hline & $\operatorname{Pr}$ & ppm & 0,020 & 0,680 & 7,950 & 1,150 & 2,090 & 109,190 & 0,460 \\
\hline & $\mathrm{Nd}$ & ppm & 0,300 & 2,400 & 33,100 & 4,400 & 8,100 & 456,300 & 1,800 \\
\hline & $\mathrm{Sm}$ & ppm & 0,050 & 0,610 & 7,910 & 1,150 & 2,030 & 113,020 & 0,580 \\
\hline \multirow{10}{*}{ 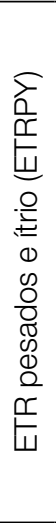 } & Eu & ppm & 0,020 & 0,140 & 2,840 & 0,340 & 0,690 & 39,500 & 0,250 \\
\hline & $\mathrm{Gd}$ & $\mathrm{ppm}$ & 0,050 & 1,040 & 9,460 & 1,360 & 2,020 & 130,580 & 1,080 \\
\hline & $\mathrm{Tb}$ & ppm & 0,010 & 0,210 & 1,630 & 0,250 & 0,370 & 22,550 & 0,240 \\
\hline & Dy & ppm & 0,050 & 1,450 & 10,030 & 1,660 & 2,540 & 137,010 & 1,810 \\
\hline & $\mathrm{Ho}$ & ppm & 0,020 & 0,370 & 0,510 & 0,430 & 0,340 & 1,960 & 26,470 \\
\hline & Er & ppm & 0,030 & 1,150 & 5,530 & 1,140 & 1,550 & 72,820 & 1,290 \\
\hline & $\mathrm{Tm}$ & ppm & 0,010 & 0,190 & 0,790 & 0,190 & 0,260 & 10,500 & 0,210 \\
\hline & $\mathrm{Lu}$ & ppm & 0,010 & 0,220 & 0,820 & 0,210 & 0,280 & 9,750 & 0,230 \\
\hline & $\mathrm{Yb}$ & ppm & 0,050 & 1,330 & 5,150 & 1,250 & 1,870 & 64,560 & 1,460 \\
\hline & Y & ppm & 0,100 & 10 & 55,200 & 8,500 & 9,60 & 694,800 & 11,100 \\
\hline & Sc & ppm & 1 & 38 & 40 & 69 & 119 & 60 & 31 \\
\hline & $\mathrm{ETRY}_{\mathrm{T}}$ & ppm & & 39,300 & 190 & 57,800 & 57,800 & $2.351,100$ & 24,700 \\
\hline & ETRL & ppm & & 23,200 & 96,600 & 42,500 & 38,100 & $1.142,500$ & 6,600 \\
\hline & ETRP & ppm & & 16,070 & 93,410 & 15,270 & 19,690 & $1.208,540$ & 18,100 \\
\hline & $\mathrm{Ce} / \mathrm{Ce}^{*}$ & & & 2,344 & 0,248 & 3,236 & 1,036 & 0,047 & 0,510 \\
\hline & $\mathrm{La}_{\mathrm{N}} / \mathrm{Yb}_{\mathrm{N}}$ & & & 2,800 & 4,540 & 2,870 & 3,140 & 4,720 & 0,930 \\
\hline
\end{tabular}



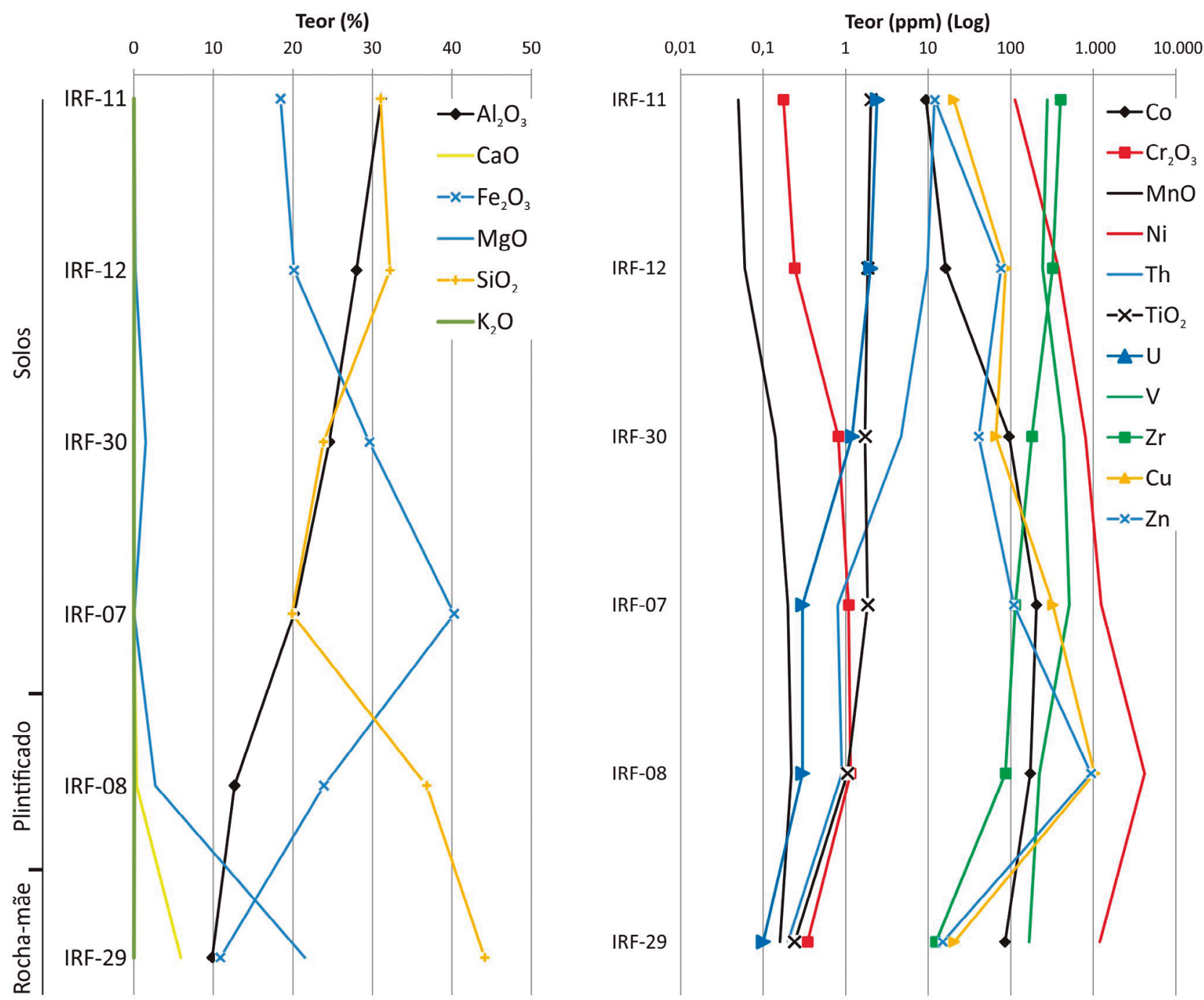

Figura 6. Variação dos teores dos principais elementos no perfil de intemperismo.

Tabela 3. Distribuição dos picos de teores, de acordo com o chemical index of alteration, dos principais metais analisados.

\begin{tabular}{|c|c|c|c|c|c|c|}
\hline Elemento & $\begin{array}{c}\text { Teor na rocha } \\
\text { (ppm) }\end{array}$ & $\begin{array}{l}\text { Pico de teor } \\
\text { (ppm) }\end{array}$ & $\begin{array}{l}\text { Amostra com } \\
\text { pico de teor }\end{array}$ & Horizonte & $\begin{array}{c}\text { Concentração em relação } \\
\text { à rocha }(\%)\end{array}$ & CIA \\
\hline$U$ & 0,100 & 2,400 & \multirow{4}{*}{$\mathrm{IRF}-11$} & \multirow{4}{*}{ Solos } & 2.400 & \multirow{4}{*}{99,800} \\
\hline Th & 0,200 & 11,900 & & & 5.950 & \\
\hline $\mathrm{Zr}$ & 12,400 & 402 & & & 3.241 & \\
\hline $\mathrm{TiO}_{2}$ & 0,240 & 2,020 & & & 841 & \\
\hline $\mathrm{V}$ & 167 & 512 & \multirow{2}{*}{ IRF-07 } & \multirow{2}{*}{$\begin{array}{c}\text { Base do } \\
\text { horizonte de solos }\end{array}$} & 306 & \multirow{2}{*}{99,700} \\
\hline Co & 85,200 & 209,400 & & & 245 & \\
\hline $\mathrm{Mn}$ & 0,160 & 0,220 & \multirow{5}{*}{ IRF-08 } & \multirow{5}{*}{$\begin{array}{l}\text { Horizonte } \\
\text { plintificado }\end{array}$} & 137 & \multirow{5}{*}{94,800} \\
\hline $\mathrm{Cr}_{2} \mathrm{O}_{3}$ & 0,346 & 1,145 & & & 330 & \\
\hline $\mathrm{Ni}$ & 1.198 & 4.204 & & & 350 & \\
\hline $\mathrm{Zn}$ & 15 & 939 & & & 6.260 & \\
\hline $\mathrm{Cu}$ & 20,600 & $1.035,100$ & & & 5.024 & \\
\hline
\end{tabular}

CIA: chemical index of alteration. 
$\mathrm{Th}, \mathrm{Zr}$ e $\mathrm{TiO}_{2}$ apresentam enriquecimento em direção ao topo do perfil, junto ao aumento do CIA, sugerindo sua presença em minerais resistatos ou, mais provável, junto a oxi-hidróxidos neoformados de Fe-Mn (Marker et al., 1991; Dickson e Scott, 1997; Ulbrich et al., 2009).

$\mathrm{Zn}$ e $\mathrm{Cu}$ apresentam empobrecimento no topo do perfil de solos. Na sequência do perfil esses elementos mostram contínuo enriquecimento, com destaque para um primeiro pico de adição na porção intermediária dos solos (IRF-12) e um segundo no saprolito (IRF-08). O segundo pico mostra o maior enriquecimento registrado para os metais, com média de 42,44, associando-se à presença de argilominerais do tipo 2:1. Esses aspectos são condizentes com a mobilidade vertical desses elementos no perfil de intemperismo.
$\mathrm{Co}, \mathrm{Mn}, \mathrm{Cr}_{2} \mathrm{O}_{3}$ e Ni apresentam empobrecimento no horizonte de solos, o qual diminui do topo para a base desse perfil. Após atingir o horizonte saprolítico esses elementos apresentam forte enriquecimento. Nesse caso, saem de um empobrecimento médio de 0,64 , na base do horizonte de solos (IRF-07), para um enriquecimento médio de 1,92 (IRF-08). Essa variação gradativa sugere migração vertical desses elementos, a qual é comum em ambiente ácido e/ou oxidante (Reimann e Caritat, 1998), migrando do horizonte de maior CIA para aquele de menor.

No caso específico do $\mathrm{Ni}$, o maior enriquecimento, coincidente com o pico de teor, se dá no horizonte contendo argilas bissialíticas (montmorillonita). $\mathrm{O}$ fato é compatível
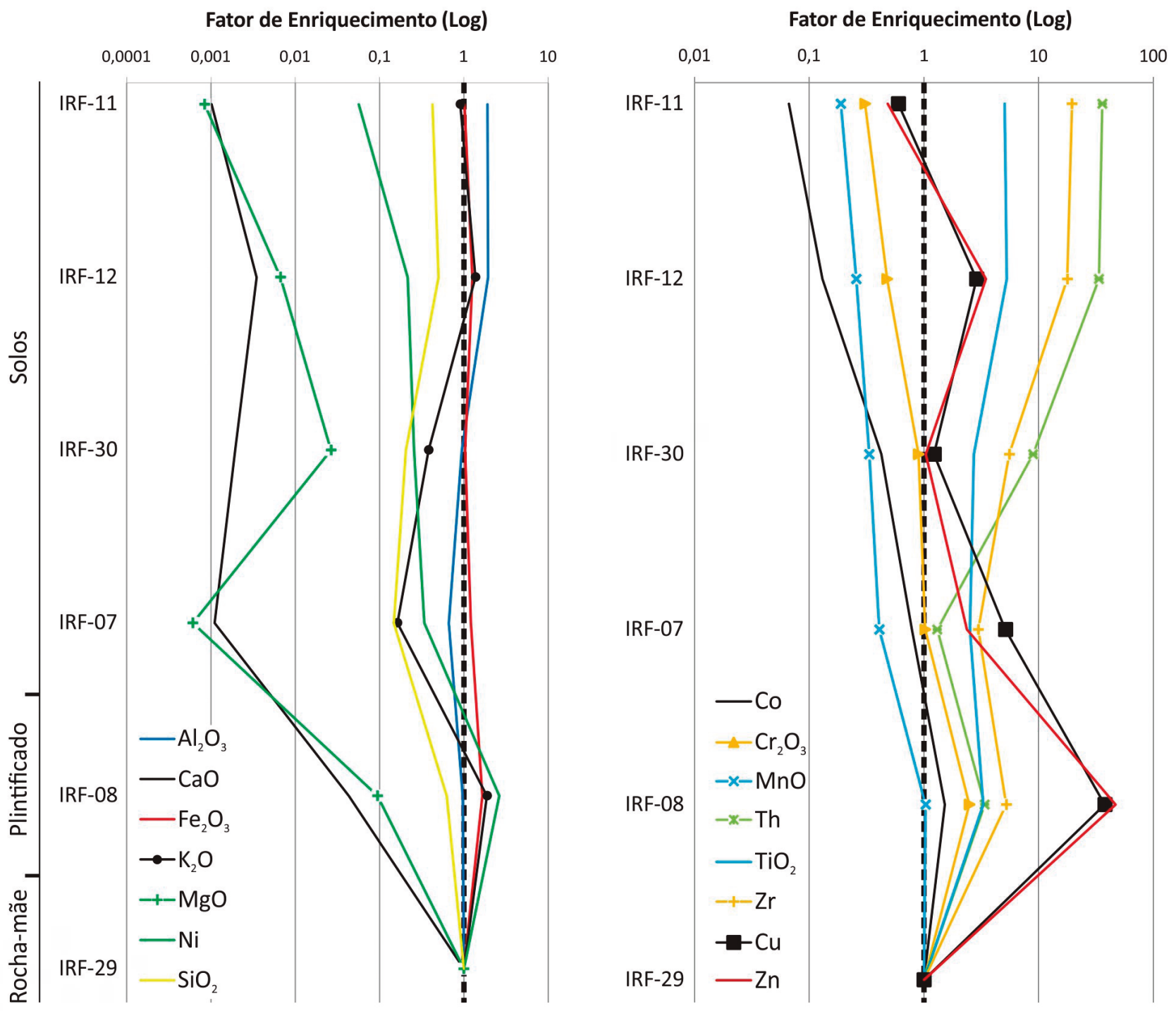

Figura 7. Fator de enriquecimento de parte dos elementos químicos no perfil de intemperismo. Calculados em relação ao Vanádio (V) (Thorne, 2011). 
com a geoquímica desse elemento, que pode ser incorporado na estrutura desses argilominerais (Marsh et al., 2013). Essa situação é equivalente ao que se observa em jazidas lateríticas desse metal do tipo "silicatos hidratados/argilas esmectíticas" (Brand et al., 1998; Marsh e Anderson, 2011; Marsh et al., 2013).

\section{Elementos terras raras}

A avaliação do conteúdo dos ETR indicou variações diferenciadas nas concentrações e nos enriquecimentos ao longo do perfil de intemperismo (Figura 8).

O cério apresentou anomalias positivas (Tabela 2) em todas as amostras dos horizontes de intemperismo (Tabela 2), indicado condições oxidantes ao longo da faixa amostrada do perfil de intemperismo (Braun et al., 1990). Apesar disso, notam-se as distinções de seu conteúdo para seus pares (La e Pr) no decorrer da análise das amostras (Figura 8), com sobressalto de seus valores no horizonte de solos e menor expressão no saprolito (IRF-08). Devido ao seu comportamento geoquímico distinto dos demais ETR, com tendência a acúmulo junto aos oxi-hidróxidos de ferro, foi tratado à parte no fator de enriquecimento. $\mathrm{O}$ elemento apresenta enriquecimento por todo o perfil, com pico na amostra do horizonte plintificado (IRF-08). Nesse local também apresenta seu maior conteúdo absoluto. Ainda assim, o Ce mostra enriquecimento inferior aos demais ETR nessa posição do perfil.

Tratando as amostras normalizadas pelo condrito (Figura 8), nota-se que, no geral, o horizonte de solos apresenta tendência de aumento dos elementos terras raras leves (ETRL - La a Sm) em relação à rocha. Já os elementos terras raras pesados (ETRP - Eu a Lu), nesse mesmo horizonte, mostram tendência geral de valores próximos ao conteúdo da rocha. Nesse caso, faz-se exceção à amostra IRF-12, que apresentou comportamento mais similar ao horizonte plintificado, o que também é visível no cálculo do $\mathrm{Ce}$ anômalo $\left(\mathrm{Ce} / \mathrm{Ce}^{*}\right)$, significativamente inferior nessa amostra de solo em relação às demais. Tal condição pode se associar a oscilações do grau de intemperismo na exposição em que foram coletadas as amostras, assim como descrito para o contato entre os horizontes avaliados. Nas avaliações petrográficas não foram observados minerais silicáticos de ETRY, como zircão - resistente ao intemperismo - , o que se deve ao baixo grau de diferenciação da rocha (Cullers e Graf, 1984). Assim, seriam necessárias avaliações adicionais para aferir a mineralogia que porta esses ETRL e que corroborem o aumento de conteúdo nesse horizonte.

Ao atingir o horizonte saprolítico, o aumento do conteúdo total de ETRY é marcante. Enquanto a rocha apresenta ETRY total de $24,7 \mathrm{ppm}$, no saprolito plintificado a soma de ETR e Y salta para 2351,1 ppm, um incremento de 95,18 vezes para esse conteúdo total. Dado que a mineralogia desse horizonte, descrita em avaliação de campo e em caracterização mineralógica, não destoa do esperado para o clorita-anfibólio xisto saprolítico, acredita-se que esse aumento de conteúdo possa ser comparado à gênese das jazidas de concentração laterítica de ETRY adsorvidos em argilas (Bao e Zhao, 2008).

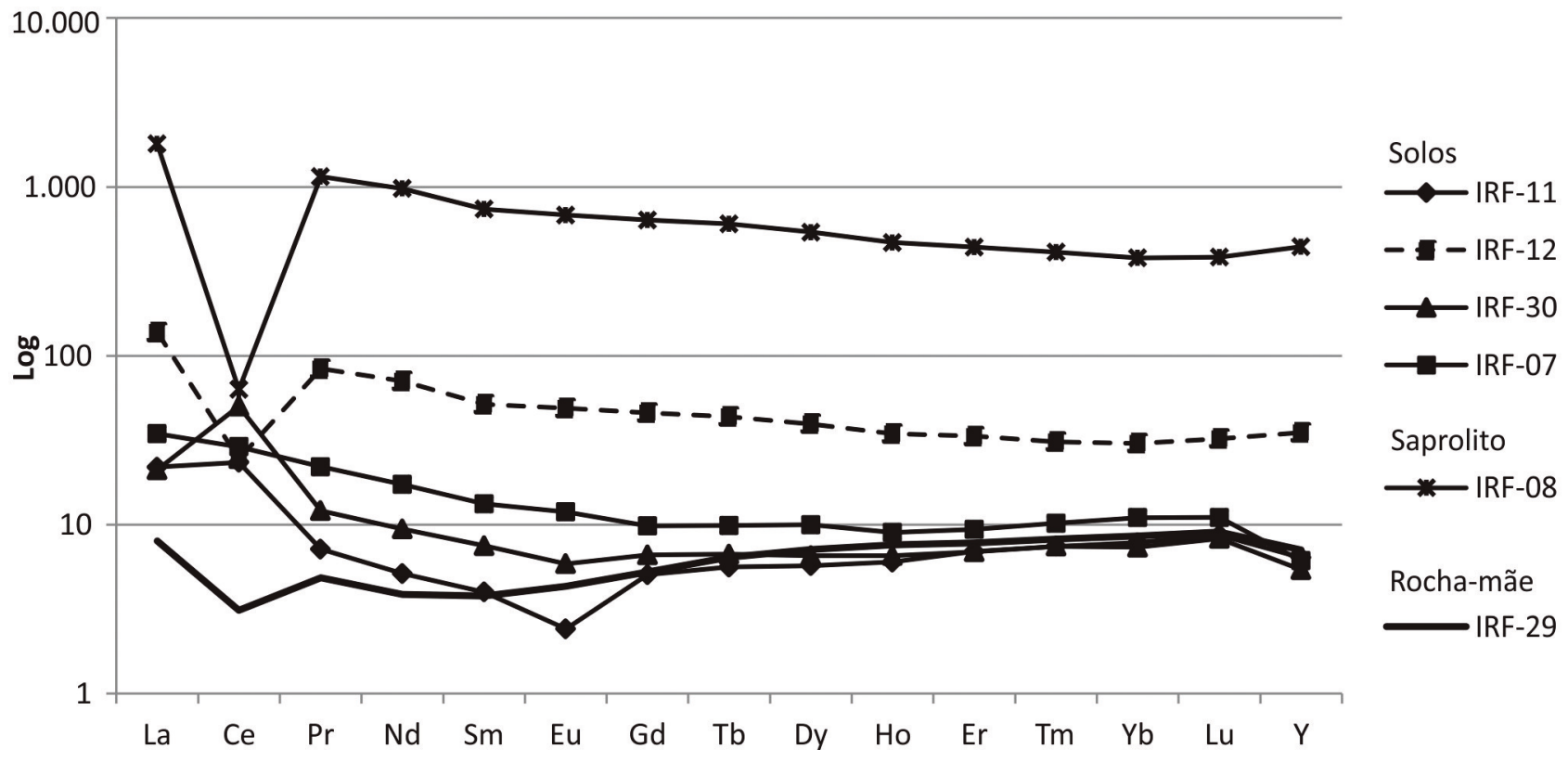

Figura 8. Distribuição dos teores de ETRY normalizados de acordo com os horizontes de intemperismo. Dados normalizados pelo condrito de Sun e McDonough (1989). 
Como a variação do conteúdo de ETR diverge de acordo com os ETRL e os ETRP, a relação $\mathrm{La}_{\mathrm{N}} / \mathrm{Yb}_{\mathrm{N}}$ reflete essa diferenciação (Tabela 3). Nesse caso, nota-se, em todas as amostras, uma tendência de maior concentração dos ETRL do que dos ETRP no perfil de intemperismo.

Assim como são observadas as mudanças dos conteúdos absolutos, os ETR apresentam distintos fatores de enriquecimento (Figura 9). Os ETRL (exceção ao Ce) e os ETRP (somados do Y) mostram similaridades entre seus fatores de concentração. Os ETRL tiveram enriquecimento ao longo de todo perfil, com pico mais proeminente no horizonte plintificado. Já os ETRP tiveram empobrecimento no horizonte de solos (exceção à amostra IRF-12) e passaram a um pronunciado enriquecimento no horizonte plintificado, similar aos ETRL. Como o pico de concentração de ETR se dá no horizonte portador de argilominerais do tipo 2:1, a adsorção desses elementos na superfície das montmorillonitas, com alta CTC, não pode ser descartada (Moldoveanu e Papangelakis, 2012).

A avaliação da variação dos conteúdos dos ETR sugere a mobilidade vertical desses elementos como resposta ao processo intempérico (Nesbitt, 1979; Bao e Zhao, 2008; Duzgoren-Aydin e Aydin, 2009). Esse comportamento é ratificado pela somatória dos aspectos de distribuição do Ce em relação aos seus pares, assim como pela variação da relação $\mathrm{La}_{\mathrm{N}} / \mathrm{Yb}_{\mathrm{N}}$ e dos conteúdos totais de ETR, com

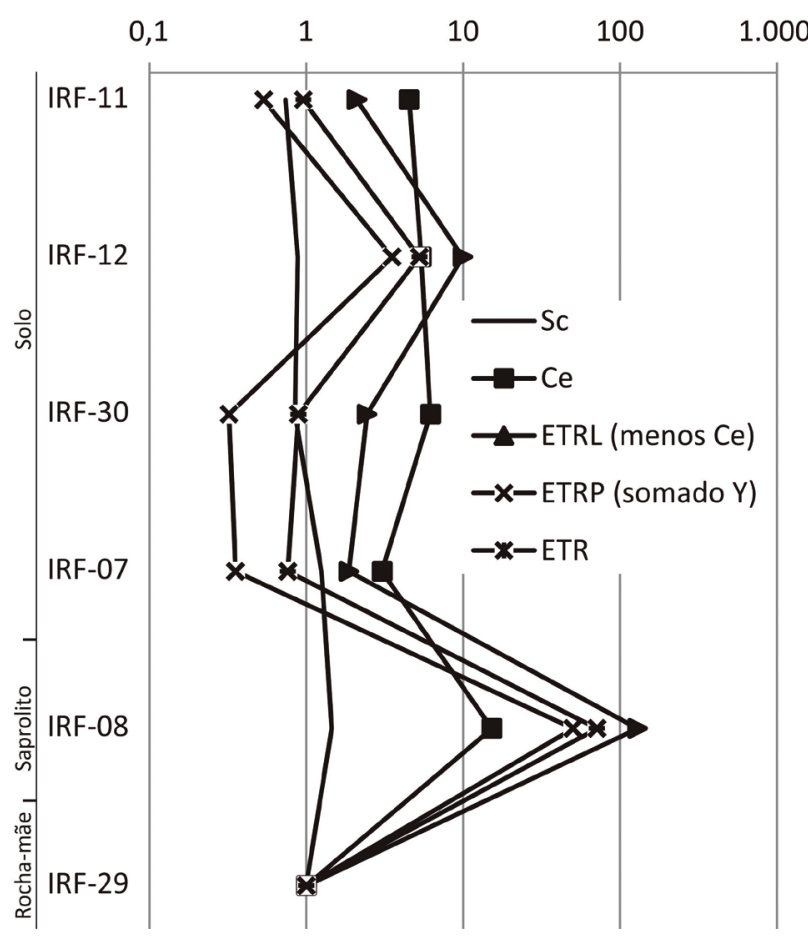

Figura 9. Fator de enriquecimento dos ETR, Y e Sc no perfil de intemperismo, calculados em relação ao vanádio (V), com fórmula apresentada em Thorne (2011). enriquecimento aumentando do horizonte de solos para o horizonte plintificado.

$\mathrm{O}$ escândio $(\mathrm{Sc})$, elemento raro e alvo de pesquisas minerais em perfis de intemperismo de rochas (meta) máficas-(meta)ultramáficas (Maulana et al., 2016), também apresentou constante incremento de teores nos horizontes de intemperismo em relação à rocha (31 ppm). Seu pico de teor foi observado na base do horizonte de solos (amostra IRF-07 - $119 \mathrm{ppm}$ ), junto ao maior conteúdo de $\mathrm{Fe}_{2} \mathrm{O}_{3}$. Essa situação, assim como descrito por Maulana et al. (2016), sugere que esse elemento químico se aloje junto a oxi-hidróxidos de $\mathrm{Fe}$, com variação de seu conteúdo decorrente da atuação do intemperismo. Apesar desse pico de teor, seu maior fator de enriquecimento foi descrito, assim como para os demais ETR, no horizonte plintificado (69 ppm), havendo empobrecimento na porção superior do horizonte de solos e enriquecimento na base desse horizonte (IRF-07) e no saprolito (IRF-08).

\section{CONCLUSÃO}

Associando as características morfológicas reconhecidas no campo com as composições químicas e mineralógicas, fica evidente que a rocha metaultramáfica estudada foi submetida a condições de pronunciado intemperismo químico, resultando em espesso perfil laterítico (Nesbitt, 1979; Melfi et al., 1980; Bao e Zhao, 2008; Marsh et al., 2013; Maulana et al., 2016). Foram identificados horizontes de intemperismo que, no local, variam entre altitudes de 950 a $1.150 \mathrm{~m}$, cuja preservação é controlada pela presença de horizonte de solos lateríticos no topo, o qual age como uma couraça diante da erosão (Melfi et al., 1980). Como descrito, a atuação dos processos intempéricos promoveu as variações dos conteúdos dos elementos químicos ao longo dos horizontes formados. Em repetidos casos foram observadas, também, indicações de mobilidade vertical desses elementos, a exemplo daqueles com empobrecimento no horizonte de solos seguido de expressivo enriquecimento no saprolito, indicando que os elementos lixiviados do horizonte superior foram acumulados no horizonte plintificado, seguindo a variação do CIA.

Do ponto de vista econômico, os fatores de concentração dos elementos metálicos nos horizontes lateríticos, além da organização mineralógica de argilas neoformadas, são comparáveis àqueles geradores de jazidas desses elementos. Como exemplo, o fator de enriquecimento de $\mathrm{Ni}$ e Co é análogo àquele gerador de jazidas lateríticas desses elementos químicos (Marsh et al., 2013). Esses indicadores apontam condições de concentração química favoráveis à prospecção mineral de metais nas rochas metaultramáficas do domínio da unidade geomorfológica que contém esse 
perfil laterítico. Além disso, corroboram a existência de pronunciado intemperismo afetando todo o substrato geológico desse domínio, assim como é descrito para a unidade geomorfológica do Planalto Poços de Caldas-Varginha (RADAMBRASIL, 1983). O entendimento desses perfis lateríticos mostra aplicação em geologia econômica, prospecção e pesquisa mineral, além de servir como embasamento para finalidades de usos do solo, como agricultura e obras de engenharia.

Junto aos elementos traços, os teores de ETRY e Sc também apresentaram assinatura de concentração laterítica residual. Esses elementos tiveram expressivo enriquecimento no horizonte saprolítico, junto aos argilominerais do tipo 2:1. O Ce anômalo apontou claras condições oxidantes no trecho estudado do perfil de intemperismo. Esses valores de ETR encontrados no saprolito são notoriamente superiores àqueles apresentados por Lima (2014) para as rochas metamáficas-metaultramáficas da região, o que comprova a ação do intemperismo na modificação e no aumento do conteúdo desses elementos. Tomando os modelos de concentrações lateríticas (Bao e Zhao, 2008; Maulana et al., 2016), os valores obtidos para os ETRY e o Sc são propícios ao prosseguimento de suas caracterizações no perfil de intemperismo.

\section{AGRADECIMENTOS}

O autor expressa seus agradecimentos ao Prof. Dr. Antenor Zanardo, pela contribuição ao trabalho, e ao Conselho Nacional de Desenvolvimento Científico e Tecnológico (CNPq), pelo auxílio 131324/2013-6.

\section{REFERÊNCIAS}

Almeida, F. F. M. (1981) O Cráton do Paramirim e suas relações com o do São Francisco. Simpósio sobre o Cráton do São Francisco e suas Faixas Marginais, 1-10. Salvador: SBG.

Bao, Z., Zhao, Z. (2008). Geochemistry of mineralization with exchangeable REY in the weathering crusts of granitic rocks in South China. Ore Geology Reviews, 33, 519-535. https://doi.org/10.1016/j.oregeorev.2007.03.005

Barbosa, O., Braun, O. P. G., Dyer, R. C., Cunha, C. A. B. R. (1970). Geologia do triângulo mineiro (Projeto Chaminés). Boletim DNPM. Rio de Janeiro: DNPM. p. 136.

Brand, N.W., Butt, C.R.M., Elias, M. (1998). Nickel laterites - Classification and features. AGSO Journal of Australian Geology and Geophysics, 17, 81-88.
Braun, J., Pagel, M., Muller, J., Bilong, P., Michard, A., Guillet, B. (1990). Cerium anomalies in lateric profiles. Geochimica et Cosmochimica Acta, 54, 781-795. https:// doi.org/10.1016/0016-7037(90)90373-S

Brito Neves, B. B., Campos Neto, M. C., Fuck, R. A. (1999). From Rodinia to Western Gondwana: An approach to the Brasiliano-PanAfrican cycle and orogenic collage. Gondwana Research, 22(3), 155-166.

Butt, C. R. M. (1975). Nickel laterites and bauxites. CSIRO Australia, Division of Mineralogy. Perth. Report FP12, 34. Austrália: CSIRO Australia, Division of Mineralogy.

Carvalho, S. G., Soares, P. C., Barbour, A. P. (1992). Mineralizações nos terrenos greenstone de Alpinópolis e Fortaleza de Minas. Geociências, 11(1), 19-47.

Cullers, R. L., Graf, J. L. (1984). Rare-earth elements in igneous rocks of the continental crust: intermediate and silicic rocks-ore petrogenesis. In: P. Henderson (Ed.), Rare Earth Element Geochemistry (v. 1, p. 275-316). Amsterdam: Elsevier.

Dardenne, M. A., Schobenhaus, C. (2001). Metalogênese do Brasil. Brasília: Editora UnB.

Dickson, B. L., Scott, K. M. (1997). Interpretation of aerial gamma-ray surveys-adding the geochemical factors. Journal of Australian Geology and Geophysics, 17, 187-200.

Duzgoren-Aydin, N. S. D., Aydin, A. (2009). Distribution of rare earth elements and oxyhydroxide phases within a weathered felsic igneous profile in Hong Kong. Journal of Asian Earth Sciences, 34, 1-9. https://doi.org/10.1016/j. jseaes.2008.03.010

Faria Júnior, I. R. (2015). Prospecção mineral de alvos potenciais ao enriquecimento supergênico de níquel no Greenstone Belt Morro do Ferro. Dissertação (Mestrado). Rio Claro: Instituto de Geociências e Ciências Exatas - UNESP.

Feola, J. L. (2004). Mineralizações auríferas hospedadas na faixa metavulcano-sedimentar Jacui-Bom Jesus da Penha - Sudoeste de Minas Gerais. Tese (Doutorado). Rio Claro: Instituto de Geociências e Ciências Exatas - UNESP.

Golightly, J. P. (1981). Nickeliferous laterite deposits. In: Skinner, B. J. (Ed.), Economic Geology. McLean: GeoScienceWorld. https://doi.org/10.5382/AV75.18 
Hasui, Y., Rodrigues, E. P., Oliveira, M. C. B., Hens, J., Morales, N., Zanardo, A., Quade, H., Nyk, R., Kuller, M. L., Frasca, M. H. B. O. (1988). Deformação por cisalhamento dúctil: modelo de transformação de rochas pré-cambrianas antigas do leste de São Paulo. São Paulo: Relatório IPT. v. 3 , n. 25908 .

Hill, I. G., Worden, R. H., Meighan, I. G. (2000). Geochemical evolution of a palaeolaterite: the Interbasaltic Formation, Northern Ireland. Chemical Geology, 166(1-2), 65-84. https:// doi.org/10.1016/S0009-2541(99)00179-5

Lawrence, M. G., Greig, A., Collerson, K. D., Kamber, B. S. (2006). Rare earth element and yttrium variability in south east Queensland waterways. Aquatic Geochemistry, 12, 39-72. https://doi.org/10.1007/s10498-005-4471-8

Lima, F. G. (2014). Evolução petrogenética das rochas máficas/ ultramáficas na área ao sul do Cráton São Francisco, entre as cidades de Fortaleza de Minas e Jacuí-MG. Dissertação (Mestrado). Rio Claro: Instituto de Geociências e Ciências Exatas - UNESP.

Marker, A., Friedrich, G., Carvalho, A., Melfi, A. (1991). Control of the distribution of $\mathrm{Mn}, \mathrm{Co}, \mathrm{Zn}, \mathrm{Zr}$, Ti and REEs during the evolution of lateritic covers above ultramafic complexes. Journal of Geochemical Exploration, 40, 361383. https://doi.org/10.1016/0375-6742(91)90048-Y

Marsh, E. E., Anderson, E. D. (2011). Ni-Co laterite deposits: a deposit model. U.S. Geological Survey Open-File Report 2011-1259. Virginia: USGS Science for a Changing World.

Marsh, E. E., Anderson, E. D., Gray, F. (2013). Nickelcobalt laterites - A deposit model. In: U.S. Department of the Interior, U.S. Geological Survey (Eds.), Mineral deposit models for resource assessment. U.S. Geological Survey Scientific Investigations Report 200-5070-H, 38.

Maulana, A., Sanematsu, K., Sakakibara, M. (2016). An overview on the possibility of scandium and REE occurrence in Sulawesi, Indonesia. Indonesian Journal on Geoscience, 3(2), 139-147. https://doi.org/10.17014/ijog.3.2.139-147

Melfi, A. J., Trescases, J. J., Oliveira, S. M. B. (1980). Les "laterites" nickélifères du Brésil. Cahiers Office de la recherche scientifique et technique outre-mer, Série Géologie, 11, 15-42.

Moldoveanu, G. A., Papangelakis, V. G. (2012). Recovery of rare earth elements adsorbed on clay minerals: I. Desorption mechanism. Hydrometallurgy, 117-118, 71-78. https://doi. org/10.1016/j.hydromet.2012.02.007
Morales, N. (1993). Evolução tectônica do Cinturão de Cisalhamento Campo do Meio na porção ocidental. Tese (Doutorado). Rio Claro: Instituto de Geociências e Ciências Exatas - UNESP.

Nesbitt, H. W. (1979). Mobility and fractionation of rareearth elements during weathering of granodiorite. Nature, 279, 206-210. https://doi.org/10.1038/279206a0

Nesbitt, H. W., Young, G. M. (1982). Early Proterozoic climate and plate motions inferred form major element chemistry of lutites. Nature, 299, 715-717. https://doi. org/10.1038/299715a0

Oze, C. J. P. (2003). Chromium geochemistry of serpentinite and serpentinite soils. Tese (Doutorado). Stanford: Geological and Environmental Sciences - Stanford University.

Pearson, M. J. (1978). Quantitative clay mineralogical analyses from bulk chemistry of sedimentary rocks. Clay and Clay Minerals, 26(6), 423-433. https://doi.org/10.1346/ CCMN.1978.0260606

Prudêncio, M. I., Gouveia, M. A., Sequeira Braga, M. A. (1995). REE distribution in presente-day and ancient surface environments of basaltic rocks (Central Portugal). Clay Minerals, 30, 239-248. https://doi.org/10.1180/ claymin.1995.030.3.07

RADAMBRASIL. (1983). Levantamento dos recursos naturais - Folhas SF 23/24. Rio de Janeiro/Vitória: Ministério de Minas e Energia, v. 32.

Reimann, C., Caritat, P. (1998). Chemical elements in the environment: factsheets for the geochemist and environmental scientist. Berlim: Springer-Verlag.

Retallack, G. J. (2010). Lateritization and bauxitization events. Economic Geology, 105, 655-667. http://dx.doi. org/10.2113/gsecongeo.105.3.655

Simões, L. S. A. (1995). Evolução tectono-metamórfica da Nappe de Passos, sudoeste de MG. Tese (Doutorado). São Paulo: Instituto de Geociências - USP.

Smirnov, V. I. (1982). Geologia de yacimientos minerales. Moscou: Mir.

Sun, S. S., McDonough, W. F. (1989). Chemical and isotopic systematics of oceanic basalts: implications for mantle composition and processes. In: A. D. Saunders, M. J. Norry (Eds.), Magmatism in the oceanic basins. Londres: The Geological Society. 
Tardy, Y., Nahon, D. (1985). Geochemistry of laterites, stability of Al-goethite, Al-hematite, and $\mathrm{Fe}^{3+}$-kaolinite in bauxites and ferricretes: an approach to the mechanism of concentration formation. American Journal of Science, 285, 865-903. http://dx.doi.org/10.2475/ajs.285.10.865

Teixeira, N. A. (1978). Geologia e petrologia e prospecção geoquímica da seqüencia vulcano-sedimentar Morro do Ferro, Fortaleza de Minas (MG). Dissertação (Mestrado). Brasília: Instituto de Geociências - UNB.

Teixeira, N. A., Danni, J. C. M. (1979). Petrologia de lavas metabásicas da Seqüência Morro do Ferro, Fortaleza de Minas (MG). Revista Brasileira de Geociências, 9(2), 151-158.

Thorne, R. L. (2011). Nickel laterites, origin and climate. Tese (Doutorado). Southampton: Faculty of Engineering, Science and Mathematics School of Ocean and Earth Science - University of Southampton.

Trescases, J. J. (1975). L'evolution geochimique supergène des roches ultrabasiques en zone tropicale; formations des gisements nickeliferes de Nouvelle-Caledonie. Paris: ORSTOM.

Trescases, J. J., Oliveira, S. M. B. (1978). Alteração dos serpentinitos de Morro do Níquel (MG). XXX Congresso Brasileiro de Geologia, 4, 1655-1669. Recife: SBG.

Ulbrich, H. H. G. J., Ulbrich, M. N. C., Ferreira, F. J. F., Alves, L. S., Guimarães, G. B., Fuchting, A. (2009). Levantamentos Gamaespectrométricos em
Granitos Diferenciados. I: Revisão da Metodologia e do Comportamento Geoquímico dos Elementos K, Th e U. Geologia USP. Série Científica, 9(1),33-53. http://dx.doi. org/10.5327/Z1519-874X2009000100003

Valeriano, C. M., Machado, N., Simonetti, I. A., Valladares, C. S., Seer, H. J., Simões, L. S. (2004). U-Pb geochronology of the southern Brasília Belt (SE Brazil): sedimentary provenance, Neoproterozoic orogeny and assembly of WestGondwana. Precambrian Research, 130(1), 27-55. http:// dx.doi.org/10.1016/j.precamres.2003.10.014

Wright, M., Belitz, K. (2010). Factors controlling the regional distribution of vanadium in groundwater. Ground Water, 48(4), 515-525. https://doi.org/10.1111/j.1745-6584.2009.00666.x

Zanardo, A. (1992). Análise petrográfia, estratigráfica e microestrutural da região de Guaxupé-Passos-Delfinópolis $(M G)$. Tese (Doutorado). Rio Claro: Instituto de Geociências e Ciências Exatas - UNESP.

Zanardo, A. (2003). Pesquisa geológica e de matérias-primas cerâmicas do centro nordeste do Estado de São Paulo e vizinhanças: sistematização crítica da produção técnicocientifica. Tese (Livre-Docência). Rio Claro: Instituto de Geociências e Ciências Exatas - UNESP.

Zanardo, A., Morales, N., Carvalho, S. G. (1990). Evolução metamórfica da porção sul do Cráton Paramirim. XXXVI Congresso Brasileiro de Geologia, 4, 19451951. Natal: SBG. 